\title{
Effect of lubricant addition on the powder properties and compacting performance of spray-dried molybdenum powders
}

\author{
H.S. Huang, Y.C. Lin, K.S. Hwang * \\ Department of Material Science and Engineering, National Taiwan University, 1, Sec. 4, Roosevelt Road, Taipei, Taiwan, ROC \\ Received 12 July 2001; accepted 21 September 2001
}

\begin{abstract}
Polymeric binders, such as polyvinyl alcohol, are usually added into molybdenum powders so that, after spray drying, large spherical agglomerates with good flow properties can be produced. Since these binders may help to reduce the friction among powders and between powders and the die wall, the necessity of mixing an additional lubricant, such as ethylene bis-stearamide (EBS), to facilitate compaction has come under question. This study investigated the effect of EBS on the apparent density, flow rate, variation on compact weight, green density, green strength, and compactability. The results show that, when flow properties, dimensional control, and low ejection force are desirable, the optimum content of EBS addition should be between $0.1 \%$ and $0.2 \%$. When high green density, green strength, and compactability are required, no lubricant should be added. (C) 2002 Elsevier Science Ltd. All rights reserved.
\end{abstract}

Keywords: Spray drying; Molybdenum; Lubricant; Compaction; Powder properties

\section{Introduction}

When fine molybdenum powders are pressed into compacts, the amount of powder filling the die cavity could vary if the powder has a poor flow rate and low apparent density. The fine powders could also flow into the clearances between the sidewall of the punch and the die, causing serious wear and scoring on the tools. To circumvent these problems, spray drying is frequently employed so that fine individual Mo particles can be transformed into large spherical agglomerates. In the spray drying process, polymeric binders, such as polyvinyl alcohol (PVA) and polyethylene glycol (PEG), are used [1-3]. With Mo particles being coated with binders, it is probable that the friction among particles and the friction between particles and the die wall are reduced. This could improve the compressibility and reduce die wear. Thus, the first objective of this study was to compare the compacting performance of the fine $\mathrm{Mo}$ powders before and after spray drying.

Quite a large amount of literature has reported the effect of lubricants in pressing metal powders [4-11]. In

${ }^{*}$ Corresponding author. Fax: $+886-2-2363-4562$.

E-mail address: kshwang@ccms.ntu.edu.tw (K.S. Hwang). general, the addition of lubricant increases the flow rate and apparent density while reducing the ejection force. It could also improve the green density, depending on the amount added. These reports have provided guidelines for the powder metallurgy industry in selecting the type and the amount of lubricant. However, very little information is available on the effect of lubricant on spray-dried powders. Thus, the second objective of this study was to investigate whether additional lubricant will further improve or, contrarily, impair the properties of the spray-dried powder.

Ethylene bis-stearamide (EBS) is a lubricant commonly used in pressing metal powders [10-14]. It contains no metallic elements, as shown by its chemical structure in Fig. 1. As it is a clean and effective lubricant, it was used in this study to evaluate its effect on the properties of spray-dried Mo powders. Apparent density, flow rate, variation of compact weight, green density, green strength, ejection force, and compactability are evaluated.

\section{Experimental procedure}

Fine Mo powder with an average particle size of $3.54 \mu \mathrm{m}$ was used in this study. Its morphology and 


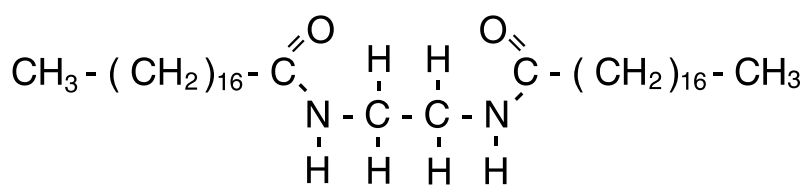

Fig. 1. The chemical structure of ethylene bis-stearamide (EBS).

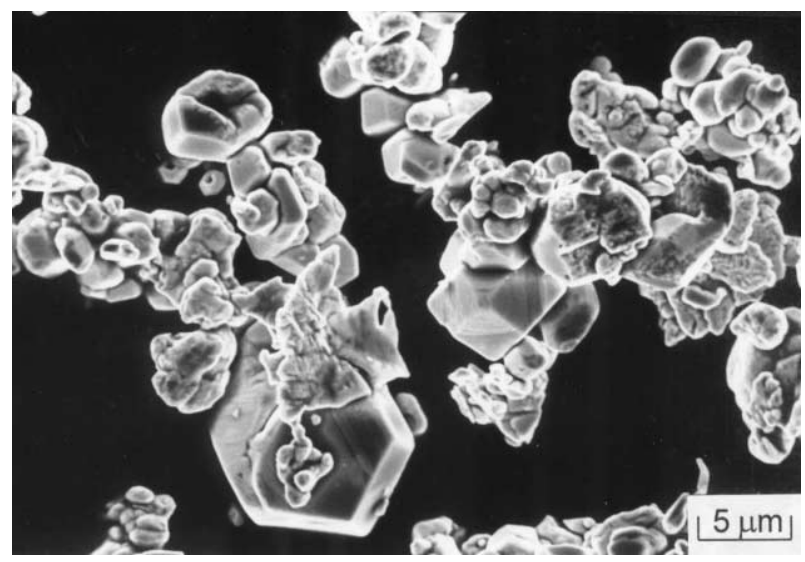

Fig. 2. The morphology of the fine molybdenum powder prior to spray drying.

characteristics are given in Fig. 2 and Table 1, respectively. With its small particle size and high surface area, the flow rate is usually too slow and the apparent density too low to be used for automated die compaction. To facilitate die filling and compaction, spray drying was employed. The Mo powder was first mixed with PVA and de-ionized water. The mixed slurry was then spray dried using heated air. Table 2 and Fig. 3 show, respectively, the characteristics and the morphology of the Mo powder after spray drying.

To evaluate the effect of EBS on powder properties, the apparent density and flow rate were examined with a Hall flowmeter using the MPIF Standards No. 4. The Arnold meter was also employed to measure the apparent density based on the MPIF Standards No. 48. For compressibility testing, a fixed amount of $7 \mathrm{~g}$ of Mo powder was pressed under various pressures into cylindrical compacts of $12.5 \mathrm{~mm}$ in diameter using a floating die technique. The ejection force was monitored during compaction. After compaction, the green strength of the compact was measured by the four-point bending

Table 1

Characteristics of the molybdenum powder used in this study

\begin{tabular}{ll}
\hline Molybdenum powder & Characteristics \\
\hline Supplier & HCST, Coldwater, MI, USA \\
$\mathrm{D}_{50}$ (Laser scattering) & $3.54 \mu \mathrm{m}$ \\
Surface area (BET) & $0.414 \mathrm{~m}^{2} / \mathrm{g}$ \\
Pycnometer density & $10.18 \mathrm{~g} / \mathrm{cm}^{3}$ \\
Tap density & $4.16 \mathrm{~g} / \mathrm{cm}^{3}$ \\
Chemistry, wt $\%$ Mo & $>99.8$ \\
\hline
\end{tabular}

Table 2

Characteristics of the molybdenum powder after spray drying

\begin{tabular}{llr}
\hline Molybdenum powder & Characteristics & \\
\hline Particle size (sieving), wt $\%$ & +100 & 0.5 \\
& +140 & 29.0 \\
& +170 & 23.5 \\
& +200 & 17.0 \\
& +230 & 13.0 \\
& +270 & 4.5 \\
& +325 & 8.5 \\
& -325 & 4.0 \\
Pycnometer density & $9.28 \mathrm{~g} / \mathrm{cm}^{3}$ & \\
Apparent density & $2.1 \mathrm{~g} / \mathrm{cm}^{3}$ & \\
Flow rate, s/50 g & 27.9 & \\
Chemistry, wt $\% \mathrm{Mo}$ & $>98.5$ & \\
$C$ & 0.88 & \\
\hline
\end{tabular}

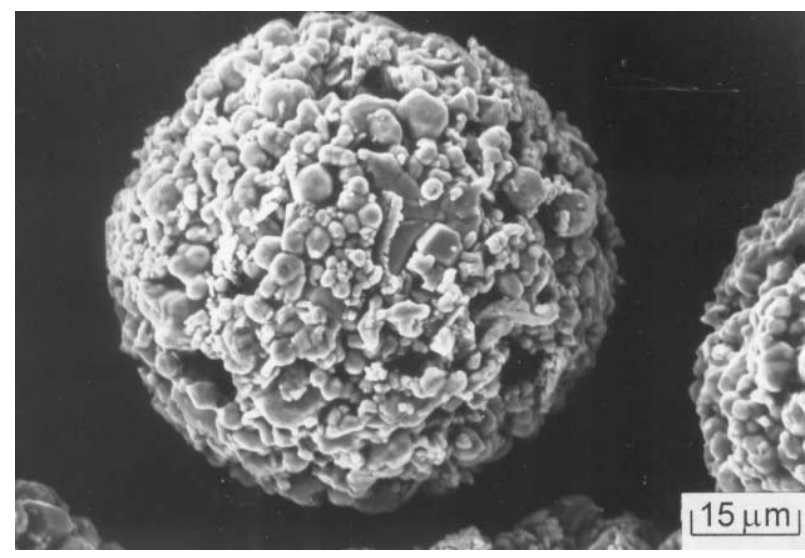

Fig. 3. The morphology of spray-dried molybdenum powder.

method; the $40 \mathrm{~mm} \times 15 \mathrm{~mm} \times 3 \mathrm{~mm}$ specimen was placed on two parallel rods $30 \mathrm{~mm}$ apart. The distance between the other two rods, which were on top of the specimen, was $10 \mathrm{~mm}$. For the compactability of the powder, the rattler tester was employed. Thirty cylindrical compacts were placed into a barrel, which was constructed by stainless steel wire meshes. The barrel was horizontally rotated at $50 \mathrm{rpm}$. After 2000 rotations, the weight losses of the compacts, which represent the integrity of the green parts, were compared.

\section{Results}

\subsection{Powder properties}

Figs. 4 and 5 show, respectively, that as the amount of EBS increased, the apparent density and flow rate measured by the Hall flowmeter improved. This means that the time required to fill a specified amount of powder into the die cavity is shortened, and thus productivity is increased. This also helps tofs reduce the thickness of the die, which is usually made of expensive 


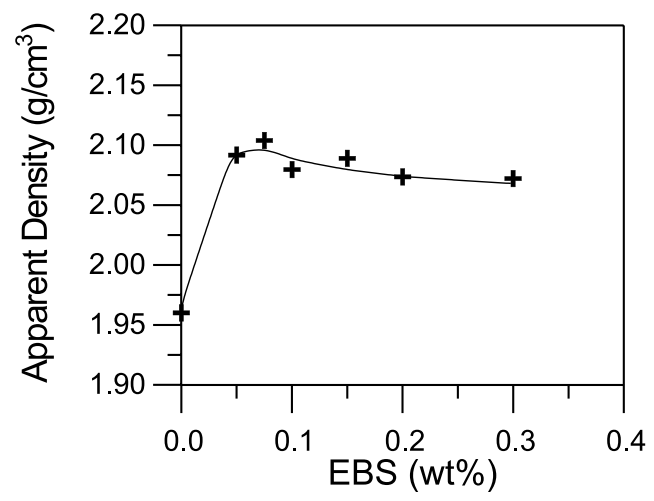

Fig. 4. The apparent density increases as EBS is added.

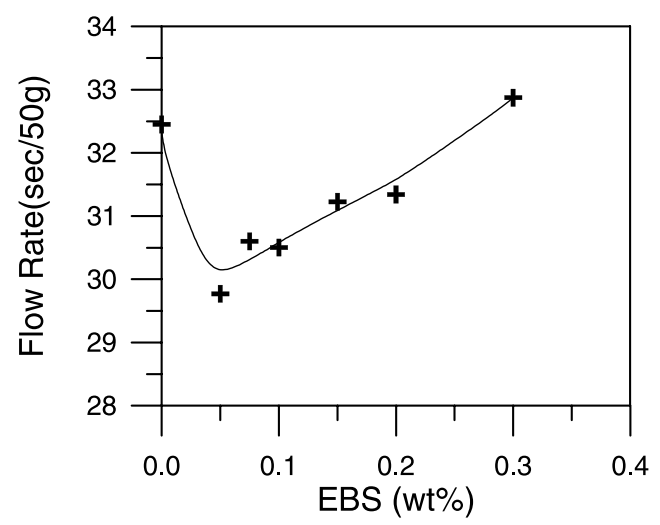

Fig. 5. The flow rate improves when less than $0.2 \%$ EBS is added.

tool steels or tungsten carbides. When the Arnold meter was used to simulate the feed shoe movement during die filling, the results shown in Fig. 6 were obtained, and these results illustrate that the variations in the compact weight decreased when the EBS was added.

The above results on apparent density, flow rate, and weight variation indicate that the addition of lubricant is

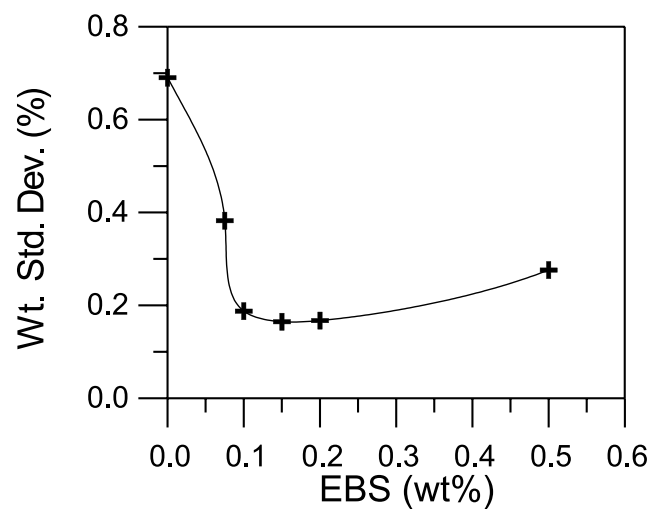

Fig. 6. The standard variation of compact weight decreases as EBS is added. beneficial and that the optimum amount should be between $0.1 \%$ and $0.2 \%$.

\subsection{Compaction performance}

Table 3 lists the green densities of Mo compacts pressed at $450 \mathrm{MPa}$. When the original $3.54 \mu \mathrm{m} \mathrm{Mo}$ powder was used, the specimen attained $6.82 \mathrm{~g} / \mathrm{cm}^{3}$, or $66.7 \%$ of the pycnometer density of Mo powders. This is slightly higher than the $6.80 \mathrm{~g} / \mathrm{cm}^{3}$ attained with spraydried powders. When the compact made of the spraydried powder was thermally debound to remove the PVA binder at $800{ }^{\circ} \mathrm{C}$, the density decreased to 6.73 $\mathrm{g} / \mathrm{cm}^{3}$. Similar trends were also found using other compacting pressures.

Fig. 7 shows the green densities of compacts pressed at $600 \mathrm{MPa}$. When the as-spray-dried Mo powder was pressed, the green density was $7.445 \mathrm{~g} / \mathrm{cm}^{3}$. With zinc stearate die wall lubrication, the green density increased to $7.470 \mathrm{~g} / \mathrm{cm}^{3}$. With EBS additions, the absolute green density decreased. The relative density, however, still increased, as illustrated in Fig. 8. This is in contrast to most ferrous powders, for which the addition of a small amount of lubricant usually produces higher green density, in both absolute and relative scales, than those without lubricant and those with die wall lubrication $[7,15]$. These results suggest that the reduction of the

Table 3

The green density, green strength, ejection force, and ejection energy of molybdenum powders prior to and after spray drying

\begin{tabular}{cll}
\hline & $\begin{array}{l}\text { Before } \\
\text { spray } \\
\text { drying }\end{array}$ & $\begin{array}{l}\text { After } \\
\text { spray } \\
\text { drying }\end{array}$ \\
\hline Green density, g/cm ${ }^{3}$ (pressed at $\left.450 \mathrm{MPa}\right)$ & & \\
As-pressed & 6.82 & 6.80 \\
After debinding & - & 6.73 \\
Green strength, ${ }^{a} \mathrm{MPa}$ (pressed at $\left.600 \mathrm{MPa}\right)$ & 29.5 & 25.1 \\
Peak ejection force, N (pressed at $600 \mathrm{MPa})$ & 22,900 & 6700 \\
Ejection energy, N-m (pressed at $600 \mathrm{MPa})$ & 398 & 215 \\
\hline
\end{tabular}

${ }^{\mathrm{a}}$ With zinc stearate die wall lubrication.

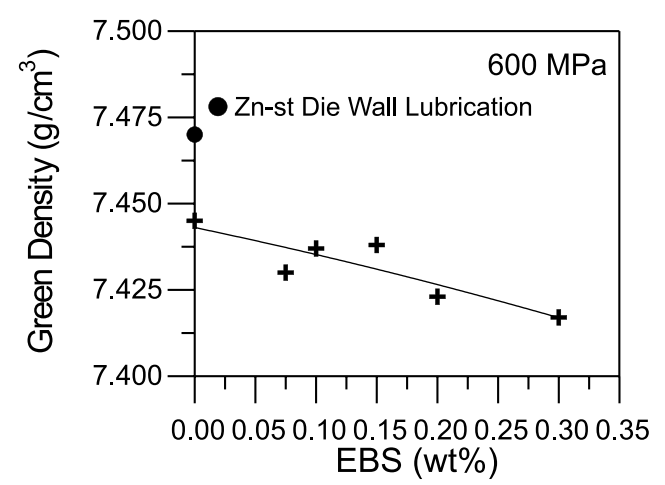

Fig. 7. The green density decreases as the amount of EBS increases. 


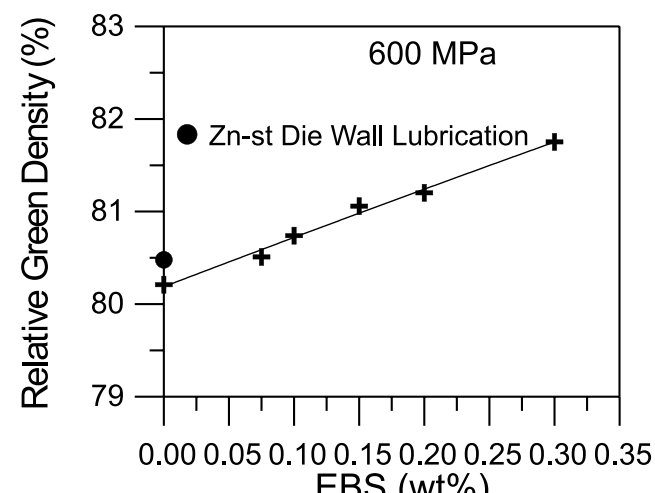

Fig. 8. The relative densities of compacts increase as the amount of EBS increases.

interparticle friction among spray-dried Mo powders by EBS is much less effective due to the presence of PVA binders. In effect, the lubrication of EBS on spray-dried powders is minimal during compaction and its effect in improving the green density is overshadowed by the increase in the total volume due to the low density of pure EBS at $1.07 \mathrm{~g} / \mathrm{cm}^{3}$.

Fig. 9 shows the typical ejection force of the Mo compact. The highest ejection force was found on the asreceived $3.54 \mu \mathrm{m}$ Mo powder, without spray drying, without EBS addition, and without die wall lubrications. After spray drying, the ejection force decreased significantly. This means that the PVA binder provides some lubrication, reducing the friction between the powder

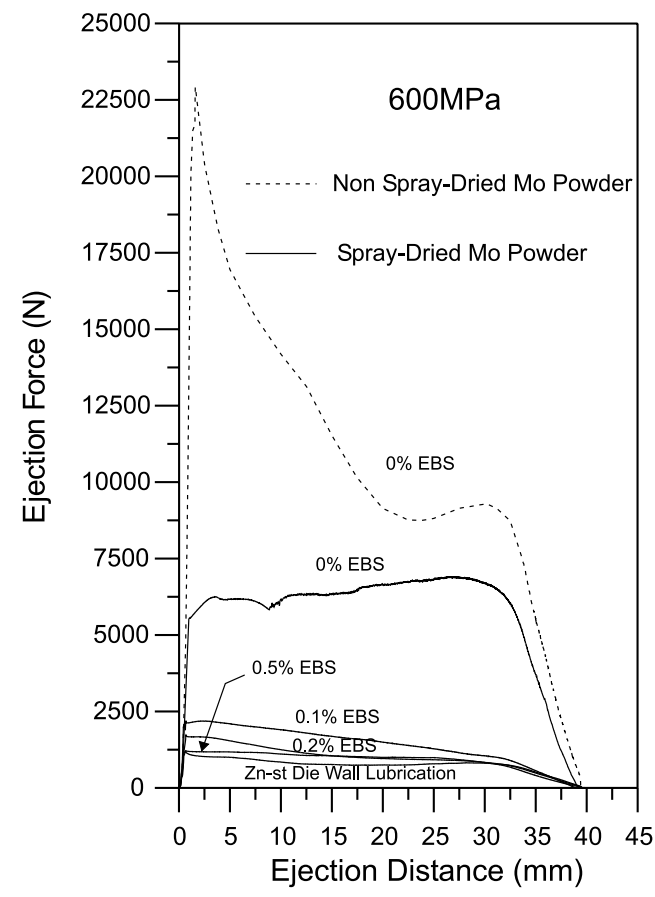

Fig. 9. The ejection forces of compacts of as-received Mo powder and spray-dried Mo powder under various lubrication conditions. and the die wall. When EBS was added into the spraydried powder, the ejection force was further decreased. The lubrication provided by the EBS could even attain results close to those of using the die wall lubrication when the amount of EBS was greater than $0.2 \%$.

The ejection energy, which is the area underneath each ejection force curve, is illustrated in Fig. 10. When the powder contained even as little as $0.1 \%$ EBS, the ejection energy decreased markedly, as in Fig. 9. With greater amounts of EBS, the ejection energy did not change much and was close to that of the use of die wall lubrication.

The above results show that the addition of EBS improves the powder flow properties and the compacting performance of spray-dried powders. Fig. 11, however, shows that it impairs the green strength of compacts due to the reduction of friction among individual Mo particles. With lower green strength, the compacts are more susceptible to breaking and chipping at the corners. Fig. 12 confirms that the greater amounts of EBS in the compact coincided with more weight loss, which was noticed during the rattler tests.

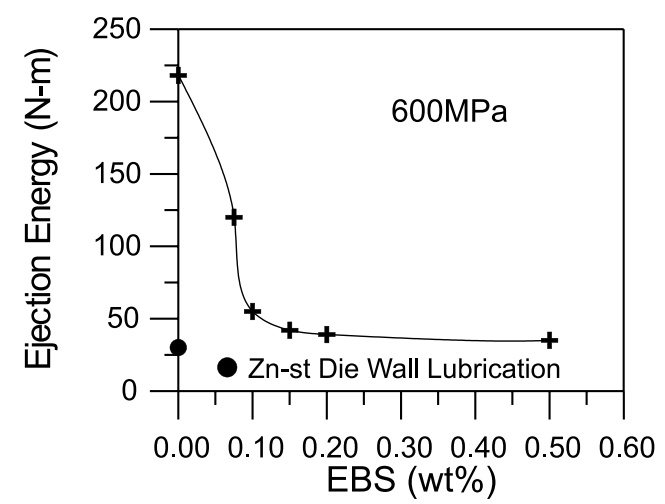

Fig. 10. The ejection energy decreases as the amount of EBS increases.

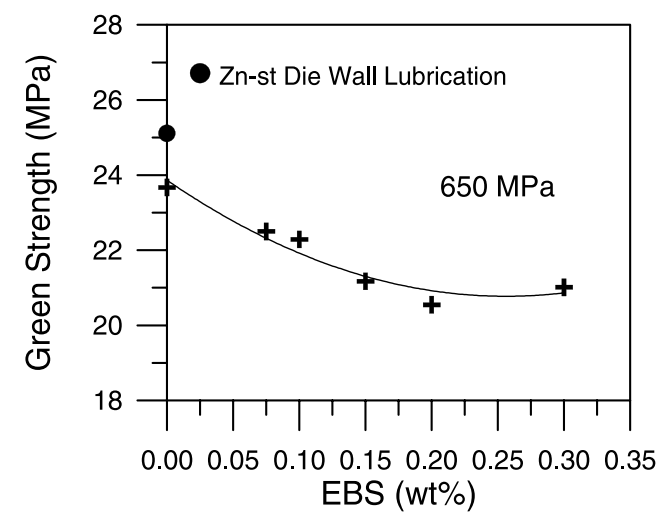

Fig. 11. The green strength of compacts decreases as the amount of EBS increases. 


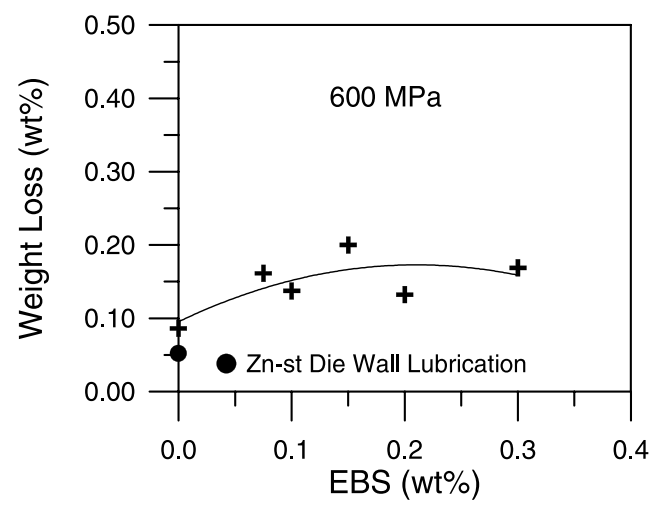

Fig. 12. The rattler test shows that as the amount of EBS increases, the weight loss of compact increases.

\section{Discussion}

\subsection{Benefits of PVA}

The main purpose of adding PVA binder to fine Mo powders is to transform them by spray drying them into spherical powder agglomerates so that good flow properties can be attained. Other than this, the most important benefit of the presence of PVA probably lies in its effect on reducing the ejection force, as shown in Fig. 9. The PVA addition, however, also has several disadvantages, such as the reduction in green strength due to the reduction of interparticle friction, and the reduction in green density due to its large specific volume. The comparison of these properties between the as-received Mo powder and the spray-dried powder is summarized in Table 3.

\subsection{Benefits of adding lubricant}

The lubricant addition usually provides several benefits during compaction, such as faster flow rate, more uniform compact weight, and lower ejection force. With less variation in the compact weight and better powder flow properties, it is expected that the green and sintered densities will be more uniform across the part. The dimensional stability should thus be improved. Moreover, the mechanical properties will also be more consistent due to the improved uniformity in sintered density and microstructure.

\section{Conclusion}

The effect of ethylene bis-stearamide (EBS) on powder properties and compacting performance of spraydried molybdenum powders was investigated. When higher apparent density, faster flow, more uniform compact weight, and, particularly, lower ejection forces are the major concerns, a small amount of EBS, less than $0.2 \%$, should be added to improve the tool life, the productivity of the press, and the dimensional stability of the compacts. However, the addition of EBS impairs the green density, green strength, and the integrity of compacts. Thus, no lubricant is needed when these properties are of more concern.

It was also noticed that the PVA binder used for spray drying has an effect similar to that of EBS lubricant. It lowers the ejection force but impairs the green strength of the compact.

\section{Acknowledgements}

The authors wish to thank Taiwan Sintered Metals for making the spray-dried powders and their financial support under contract number 88-S-018.

\section{References}

[1] Nies CW, Messing GL. Effect of glass-transition temperature of polyethylene glycol-plasticized polyvinyl alcohol on granule compaction. J Am Ceram Soc 1984;67(4):301-4.

[2] Morell A, Eranian A, Peron B, Beuzelin P. On the plastification of PVA by PEG. In: Srivastava CM, Patni MJ, editors. Advances in Ferrites, Proceedings of the Fifth International Conference on Ferrites. New Delhi, India: Oxford \& IBH; 1989. p. 137-42.

[3] Masters K. Spray drying handbook. 5th ed. New York: Wiley; 1991.

[4] Ward M, Billington JC. Effect of zinc stearate on apparent density, mixing, and compaction/ejection of iron powder compacts. Powder Metall 1998;4:201-8.

[5] Kao A, Koczak MJ. Mixing and compacting behavior of ferrous powders. Int J Powder Metall Powder Tech 1980;16(2):105-21.

[6] Ernst E, Thümmler F, Beiss FP, Wähling R, Arnhold V. Friction measurement during powder compaction. Powder Metall Int 1991;23(2):77-83.

[7] Trudel Y, Gagné M. Compaction behaviour of high compressibility low alloy steel powders. In: Gasbarre TG, Jandeska WF, editors. Advances in powder metallurgy, vol. 1. Princeton, NJ: MPIF; 1989. p. 63-73.

[8] ElWakil SD, Davies R. Lubrication effects in the compaction of sponge-iron powder at low and high speeds. Powder Metall 1973;16(31):73-87.

[9] Solimannezhad N, Larsson R. Measurement of friction during metal powder compaction. In: Proceedings of the 1998 PM World Congress, vol. 2. Shrewsbury, UK: EPMA; 1998. p. 120-5.

[10] Styskin VS. Influence of lubricants on green and sintered properties of P/M materials. In: Rose CL, Thibodeau MH, editors. Advances in powder metallurgy and particulate materials, vol. 1. Princeton, NJ: MPIF; 1999. p. 2-45-52.

[11] Knopp WV. Effect of the lubricant on green strength. In: Lawley A, Swanson A, editors. Advances in powder metallurgy and particulate materials, vol. 2. Princeton, NJ: MPIF; 1993. p. 27-33.

[12] German RM, Christian KDJ, Sacher RS, Hall L, Reinert J. A comparative evaluation of lubricants for ferrous structural alloys. In: Carlson EA, Gaines G, editors. Progress in powder metallurgy, vol. 42. Princeton, NJ: MPIF; 1986. p. 405-18.

[13] Lawrence AI, Luk SH, Hamill JA. A performance comparison of current $\mathrm{P} / \mathrm{M}$ lubricants and routes to improvement. In: 
McKotch RA, Webb R, editors. Advances in powder metallurgy and particulate materials, vol. 1. Princeton, NJ: MPIF; 1997. p. 4-3-21.

[14] Metz PA, Wolfe J, German RM, Griffo A, Steranko RT. Improved control of lubricant particle size distribution and the effects of particle size on P/M processing. In: Cadle TM, Narasimhan KS, editors. Advances in powder metallurgy and particulate materials, vol. 1. Princeton, NJ: MPIF; 1996. p. 6-59-71.

[15] German RM. In: Powder metallurgy science. Princeton, NJ: MPIF; 1994. p. 181. 